\title{
Corpos em relação: contribuições das epistemologias feministas para uma prática obstétrica situada
}

\author{
Relationships between bodies: contributions from the feminist \\ epistemologies towards a situated obstetric practice
}

Priscila Kiselar Mortelaro', Jessica Fernandes Cirelli2

DOI: 10.1590/0103-11042021E113

RESUMO Neste artigo, confronta-se o modelo tecnocrático dominante com práticas de assistência ao parto baseadas em outros paradigmas de produção de conhecimento, buscando fornecer uma alternativa à assistência intervencionista que se consolidou ao longo da história da obstetrícia. Em um primeiro momento, discute-se a emergência de uma prática obstétrica tecnocentrada e universalizante na medida em que o parto passa a se inscrever no âmbito de uma medicina com pretensões científicas. Em seguida, realiza-se uma reflexão sobre a própria produção de conhecimento a fim de apresentar elementos que possam embasar uma prática que expresse outro posicionamento epistêmico. Com inspiração nas reflexões de Donna Haraway, reflete-se sobre uma prática situada, que se volta ao particular e incorpora outros modos de produção de conhecimento no processo de tomada de decisão e ação.

PALAVRAS-CHAVE Conhecimento. Feminismo. Parto humanizado.

\begin{abstract}
In this essay, we contrast the prevailing technocratic model of childbirth care, described by Robbie Davis-Floyd, with practices based on other paradigms. Our aim is to provide an alternative to the interventionist model that has been consolidated throughout the history of modern obstetrics. At first, we discuss the emergence of a technocentric and universalizing obstetric practice, as childbirth becomes an object of knowledge of the scientific medicine. Afterwards, we carry out a reflection on the production of knowledge itself, in order to present elements to support a practice that expresses a different epistemic perspective. Inspired by Donna Haraway's contributions regarding the nature of objectivity, we propose a situated practice, which turns to the particular experiences of childbirth and incorporates other modes of production of knowledge in the decision-making process.
\end{abstract}

KEYWORDS Feminism. Humanizing delivery. Knowledge.

\footnotetext{
1 Pontifícia Universidade Católica de São Paulo (PUC-SP) - São Paulo (SP), Brasil. priscilamortelaro@gmail. com Branca (SP), Brasil.
} 


\section{Introdução}

Aquilo que Brigitte Jordan ${ }^{1}$ chamou de conhecimento legítimo, ou authoritative knowledge, constitui a base que sustenta as condutas de profissionais de saúde na atenção ao parto ou em outros contextos de assistência. Seja no modelo tecnocrático, humanista ou holístico, os três paradigmas de atenção ao parto descritos por Robbie Davis-Floyd ${ }^{2}$, todo processo de tomada de decisão e ação na assistência ao parto é validado por conhecimentos considerados legítimos no âmbito de cada um desses modelos. Desse modo, os critérios que determinam que tipo de conhecimento pode ser utilizado para respaldar condutas serão diferentes entre os modelos de assistência ao parto fundamentados em paradigmas distintos.

Antes de prosseguirmos, faz-se necessário situar brevemente os modelos descritos por Davis-Floyd ${ }^{2}$. Conforme enunciamos, além do modelo tecnocrático, existem dois outros modelos de atenção ao parto: o modelo holístico e o humanizado. Segundo a autora, cada um deles tem um modo específico de interpretar o corpo com o qual lidamos na assistência. Enquanto o modelo tecnocrático trabalha com o corpo máquina, o modelo humanizado ressignifica esse corpo, passando a compreendê-lo como um organismo. Já o modelo holístico, insistindo na unidade entre corpo, mente e espírito, o define como um campo de energia em constante interação com outros campos de energia. A contribuição da autora é inestimável para que possamos vislumbrar mudanças no cenário de assistência obstétrica, uma vez que reconhecer a possibilidade e a existência de outros modelos é reconhecer que outros regimes de produção de conhecimento podem embasar decisões e condutas no cotidiano das práticas de atenção ao parto.

O modelo tecnocrático, hegemônico em países como os Estados Unidos e o Brasil2, encontra seu respaldo em uma concepção mecânica do trabalho de parto. Por meio da paulatina introdução de tecnologias para a condução do processo e da consolidação do parto como objeto de investigação da medicina, a obstetrícia moderna afastou-se da semiologia médica, tornando-se uma disciplina que inscreve o corpo feminino na concepção mecanicista das ciências naturais ${ }^{3}$. Nesse modelo, determina-se qual é o trabalho de parto eutócico ou distócico mediante parâmetros universais. Tais critérios também são a base para o manejo das intercorrências, já que podem gerar protocolos aplicáveis em qualquer situação. Apesar da pretensão de produzir parâmetros generalizáveis, investidos de uma roupagem científica, muitas práticas e condutas de rotina são determinadas arbitrariamente ou por experiências de figuras de autoridade no campo obstetrícia. Nesse contexto, a autoridade é privilégio daqueles/ as que detêm o saber médico e que estão habilitados a fazer uso dele.

Nas últimas décadas, parteiras e pesquisadoras vêm colocando em questão o modelo tecnocrático e as bases epistêmicas que fundamentam a tomada de decisão e ação na prática obstétrica moderna. Tanto aquelas, no contexto acadêmico, quanto estas, em suas práticas cotidianas, contribuem para que novos modelos de atenção ao parto sejam possíveis. Por intermédio do gesto crítico, colocam em questão a autoridade soberana do/a detentor/a do saber médico, bem como as fórmulas padronizadas e generalizáveis que baseiam a tomada de decisão e ação.

Diametralmente oposto ao modelo tecnocrático, o modelo holístico introduz elementos que extrapolam a racionalidade. $\mathrm{O}$ estudo publicado por Davis-Floyd \& Davis ${ }^{4(239)}$ relata a experiência de parteiras que utilizam a intuição para basear seu processo de tomada de decisão e ação. Fundamentadas no paradigma holístico, no qual interioridade e conexão predominam sobre a objetividade científica, para essas parteiras, a intuição seria uma fonte de conhecimento legítimo que se diferencia das formas lineares de raciocínio dedutivo e indutivo, caracterizando-se como "outro tipo de conhecimento - profundamente encarnado". 
Entre uma assistência mecanicista e tecnocentrada, executada por meio de protocolos, e uma assistência fundamentada pelos princípios de conexão e integração com o todo, Davis-Floyd ${ }^{2}$ aponta ainda outra possibilidade. Segundo a antropóloga, o paradigma humanizado emerge da crítica aos excessos da tecnomedicina. A emergência desse paradigma inicia uma ampla transformação na assistência ao parto. Partindo da crítica à centralidade da tecnologia e da soberania do saber médico, o processo de humanização das práticas se apresenta como uma estratégia de resistência à medicalização dos corpos femininos. Simone Diniz ${ }^{5}$ destaca que o movimento pela humanização da atenção ao parto encontra na Medicina Baseada em Evidências (MBE), uma verdadeira aliada contra intervenções desnecessárias na assistência obstétrica. Isso porque a MBE se apresenta como um contraponto à medicina tradicional, que, mesmo ancorada em conhecimentos científicos, tem suas práticas baseadas fundamentalmente nas experiências individuais dos médicos tidos como autoridades no assunto ${ }^{6}$. Apesar da centralidade da MBE no movimento de humanização, seu potencial transformador não se limita a isso. Humanizar o parto pode contribuir para que outros saberes sobre esse sejam desassujeitados e legitimados.

Nesse contexto, faz-se necessário refletir sobre os princípios epistemológicos que fundamentam esse modelo de atenção ao parto e que possibilitam uma assistência cujo processo de tomada de decisão e ação considera as necessidades de cada corpo parturiente, localizado no tempo e no espaço. Nesse contexto, realizamos uma reflexão sobre a produção de conhecimento partindo das epistemologias feministas, trazendo as contribuições de Donna Haraway sobre saberes localizados e de Sandra Harding acerca da noção de objetividade forte e situada. Tal discussão pode fundamentar práticas de assistência ao parto que não recusem a objetividade, mas que a ressignificam, assim como as epistemologias feministas o fizeram. Com o presente artigo, esperamos contribuir para a consolidação de novos modelos de atenção que emergem de uma crítica ao paradigma tecnocrático e para o fortalecimento de outros modos de se relacionar com o próprio corpo por intermédio desses discursos e práticas de assistência alternativos. Para tanto, acreditamos ser necessário nos voltarmos às experiências reais de assistência ao parto, para que possamos nos contrapor às prescrições e idealizações que incidem sobre os corpos femininos.

\section{A consolidação do modelo tecnocrático}

Segundo Davis-Floyd ${ }^{2}$, o modelo tecnocrático é fruto de uma medicina que reflete o âmago do sistema ocidental de valores. Sua hegemonia está fundamentada na autoridade científica - apesar de, curiosamente, a maioria dos procedimentos obstétricos não serem baseados em evidências científicas, mas no argumento de autoridade que emana da ciência -, forjado pela tecnologia e implementado por meio de grandes instituições governadas por ideologias patriarcais inseridas em um contexto econômico orientado pelo lucro.

O modelo em questão posiciona a mulher parturiente como objeto de uma prática cujo sujeito é o/a médico/a, reproduzindo uma dicotomia subjacente que opera como um de seus princípios, opondo a mente e o corpo entendido como máquina àquele/a que detém o saber e o corpo a ser controlado. Baseado na organização hierárquica e na padronização do cuidado, ciência e tecnologia são supervalorizadas no modelo tecnocrático. Consequentemente, autoridade e responsabilidade são inerentes à/ao profissional e não à parturiente. Basicamente, caracteriza-se como um modelo intolerante a outras práticas de atenção ao parto².

Mary Jane Spink ${ }^{3}$ destaca que a institucionalização da medicina e seu desenvolvimento científico têm relevância central para que possamos compreender como o parto se 
tornou objeto de tomada de poder. Esse processo de institucionalização se iniciou entre os séculos XII e XIII. Nessa época, apesar de não ser restrita a grupos específicos, a prática médica passou a ser condicionada ao porte de licenças obtidas por meio da educação universitária. O desenvolvimento das corporações de cirurgiões-barbeiros e apotecários deu condições para a profissionalização da prática médica, que se consolidou por intermédio de um movimento de exclusão daqueles/as que não tinham licenças. Esse foi um primeiro passo em direção à desqualificação daqueles que não possuíam formação para o exercício da cura. No entanto, a caça às bruxas também foi fundamental para a legitimação do profissional médico formado pelas universidades, uma vez que contribuiu para a degradação do papel dos/as curandeiros/as, principalmente das práticas femininas de cura. Essa perseguição contribuiu para a consolidação da profissão médica, mediante uma aliança entre médicos e igreja, na qual o exercício da profissão era fiscalizado pelas autoridades eclesiásticas. Nesse contexto, privilegiou-se uma medicina formal, de cunho teológico, baseada, em grande parte, na obra de Galeno, em oposição ao conhecimento adquirido por meio da experiência, exercido basicamente por mulheres e transmitido por redes informais ${ }^{3}$.

Embora a medicina já tivesse se institucionalizado, com a emergência da biopolítica, no século XVIII, ela se consolidou como uma tecnologia de poder que se dirige à população, tomando-a como uma massa que é afetada por processos que são próprios à vida - natalidade, mortalidade, longevidade - e que devem ser regulados 7 . A partir de então, a disciplina tornou-se um dispositivo fundamental para regular as condições adversas à saúde que poderiam afetar a força de trabalho da população que, segundo Foucault ${ }^{7}$, estava em vias de explosão demográfica e industrialização. Para regular, no entanto, é preciso conhecer, de modo que o século seguinte foi marcado pela medicina experimental e pela introdução de novos modos de prática médica, no âmbito das quais os médicos passaram a se colocar como peritos das questões relativas à saúde do corpo e da população ${ }^{3}$.

Apesar de a consolidação de uma medicina científica ter se dado apenas no século XIX, devemos destacar que já havia certa participação masculina no parto que data desde os cirurgiões-barbeiros. Tal participação na assistência ao parto acabou criando uma divisão entre a obstetrícia não cirúrgica, exercida pelas mulheres parteiras, e a obstetrícia intervencionista, aplicada aos partos difíceis e que requeriam técnicas cirúrgicas. A diferença entre os tipos de atenção ao parto realizada por parteiras e médicos com formação profissional se intensificou com o surgimento de tecnologias, como a introdução do fórceps no século XVII. Ainda que não houvesse proibições sobre o uso dessas tecnologias pelas parteiras, essa diferenciação pode ser atribuída à resistência a uma abordagem intervencionista por parte destas ${ }^{3}$.

Mesmo diante de certa participação masculina na atenção ao nascimento, o parto e a saúde reprodutiva, especificamente, permaneceram como domínios de atividade predominantemente feminina até o fim do século XIX, período que se caracterizou pelas descobertas da medicina científica. Isso porque havia uma diferença nos resultados entre a assistência realizada por parteiras e médicos, uma vez que esta estava associada a maiores níveis de morbimortalidade feminina em decorrência de infecções provocadas por procedimentos cirúrgicos. No entanto, os novos conhecimentos nos campos da medicina e da microbiologia contribuíram para a melhora dos desfechos de partos cirúrgicos e instrumentais. A partir de observações sistemáticas realizadas por médicos como Wendell-Holmes, nos Estados Unidos, e Semmelweiss, na Áustria, introduziu-se uma das medidas mais simples e efetivas para a prevenção de infecções puerperais: a higienização das mãos após o contato com as parturientes ${ }^{3}$.

Nesse contexto, o controle das infecções e a diminuição da prevalência da febre puerperal nos partos instrumentais permitiram que se consolidasse uma assistência obstétrica hospitalar, masculinista e intervencionista ${ }^{3}$. Embora 
ainda existam parteiras, a partir do século XIX, o controle e a administração do processo de parturição passaram a ser, nas sociedades ocidentais, prerrogativa dos médicos.

Sem dúvida, o percurso histórico descrito acima é fundamental para a emergência e a consolidação do modelo tecnocrático de atenção ao parto. No entanto, é preciso ressaltar que a emergência desse modelo não deve ser compreendida apenas à luz da institucionalização da medicina. A história da intensa medicalização do parto é, principalmente, uma questão de gênero. Acima, pudemos perceber que esse processo de institucionalização operou um processo de desqualificação e marginalização do ofício das parteiras em função da ascensão dos médicos na atenção ao parto. Antes prerrogativa feminina, a atenção ao parto passou a ser de domínio quase exclusivo dos homens, já que, por muito tempo, apenas eles tiveram acesso à formação científica ${ }^{8}$.

Todavia, esse não é o único aspecto da atenção ao parto atravessado por relações assimétricas de gênero. A história do modelo hegemônico diz respeito também ao processo de patologização do corpo feminino e ao modo como esse corpo, por meio do dispositivo da sexualidade, tornou-se um dos conjuntos estratégicos sobre os quais o poder sobre a vida se organiza, sendo inscrito nos mais variados mecanismos de normalização e controle ${ }^{9}$. Integrado ao campo das práticas médicas, o corpo feminino foi redefinido como um corpo fundamentalmente patológico: tudo que a medicina tinha a dizer sobre esse corpo comprovava seu caráter naturalmente falho. Em relação ao parto, Diniz destaca que a medicina moderna reinterpretou e multiplicou os perigos e os sofrimentos que o envolvem. Marcado pela emergência da biopolítica, o século XVIII operou um deslocamento das bases que sustentavam esse pessimismo sexual e reprodutivo ${ }^{10}$. Antes fundamentado no pensamento cristão, o discurso médico passou a utilizar a noção de natureza como recurso para 'demonstrar' como nossos corpos teriam marcos naturais intransponíveis. Já no século
XIX, a medicina se apresentava como a grande ciência capaz de traduzir para a ordem social os desígnios naturais. À ginecologia, grande novidade da época, e à obstetrícia, cabiam esmiuçar o corpo feminino e descrevê-lo ${ }^{11}$. Conforme destaca Ana Paula Vosne Martins ${ }^{\mathbf{1 2}}$, no século XIX, a obstetrícia tomou o corpo materno como um território analisável, mensurável e passível de intervenção. Do mesmo modo, o parto também foi submetido ao exame minucioso dos médicos; e o conhecimento produzido sobre os mecanismos desse processo teve grande impacto na extensão do controle médico sobre o corpo feminino.

Apesar dos deslocamentos operados pelo século XVIII e da crescente afirmação da medicina como campo privilegiado de produção de saberes sobre o corpo feminino e o parto, a atenção domiciliar prestada por parteiras persistiu até o fim do século de XIX, visto que, por muito tempo, as mulheres resistiram ao parto assistido por médicos em ambiente hospitalar. No início do século XX, deu-se início ao paulatino deslocamento da atenção domiciliar para a atenção hospitalar, endossado por autoridades do campo da medicina obstétrica ${ }^{13}$. Uma vez no hospital, diminuem os entraves para que as mulheres fossem submetidas a toda sorte de intervenções em função da conveniência dos médicos e da instituição.

\section{Parto, ciência e normatividade}

É certo que a obstetrícia moderna pôde se consolidar como efeito de uma tecnologia de poder que incide sobre a vida com efeitos reguladores e disciplinadores sobre os corpos femininos. No entanto, no cerne do processo de consolidação desse modelo, está um deslocamento, a saber, uma mudança epistêmica. As práticas de atenção ao parto deixaram de se restringir à tradição da semiótica do diagnóstico médico e passaram a se ancorar na racionalidade científica moderna. Segundo essa racionalidade, a validade do conhecimento produzido sobre 
os corpos femininos, e que fundamenta toda prática obstétrica, decorre de sua objetividade. Essa objetividade é baseada em certos princípios, que, conforme afirma Alberto Culpani ${ }^{14}$, normatizam os critérios segundo os quais legitimamos o conhecimento e sua correspondência ao objeto. No âmbito da ciência tradicional, maximizá-la pressupõe neutralidade e imparcialidade e garantiria a universalidade do conhecimento. Nesse contexto, a obstetrícia hegemônica passou a ser validada por conhecimentos que generalizam o corpo feminino, resultando em práticas que deixam de estar ancoradas na singularidade de cada corpo.

Nesse processo, o trabalho de parto foi instituído como objeto de conhecimento da medicina científica. Por meio dela, não apenas se produzem normas relativas às características esperadas do processo de parturição, mas estas passam também a ser tidas como fatos. O tempo de duração de cada parto, por exemplo, passou a ser avaliado e conduzido tendo como medida aquilo que se entende por trabalho de parto normal, determinado estatisticamente mediante estudos experimentais no âmbito da expertise médica, do qual derivam recomendações e diretrizes que devem ser seguidas pelos/as profissionais. $\mathrm{Na}$ ânsia de definir o que é o parto normal, a obstetrícia com pretensões científicas passou a prescrever o parto ideal. Para que o parto real coincidisse com o processo idealizado, uma série de intervenções e práticas obstétricas passaram a ser realizadas rotineiramente, de maneira protocolar ${ }^{15}$.

Conforme destaca Georges Canguilhem ${ }^{16}$, no âmbito da medicina com pretensões científicas, estabeleceu-se uma perigosa coincidência entre a norma e a média. Na tarefa de determinar as funções e os processos vitais normais, a fisiologia teria encontrado na média seu correspondente "objetivo e cientificamente válido"16(59). Desse modo, o que chamamos de valores biológicos normais são, na verdade, constantes determinadas estatisticamente, e os processos e estados do organismo que consideramos normais são aqueles que estão em conformidade com esses valores. Ao abrirmos um livro de obstetrícia, por exemplo, ele nos dará os parâmetros que devem ser utilizados para determinar o que é um trabalho de parto normal, seus períodos clínicos e a duração normal de cada um deles.

A coincidência entre o normal e a média na tradição médica leva à prática dos protocolos e universalizações, deixando pouco espaço para a singularidade de cada corpo. Ao contrário da relação que se consolidou com a fisiologia médica, há uma "independência lógica"16(50) entre norma e média, de modo que uma média objetivamente calculada não permite que deduzamos dela o que é a norma fisiológica. Se uma média objetivamente calculada não pode servir para determinar o que é ou não normal, também não seria adequado aplicá-la para determinar o que é patológico. Nesse sentido, um estado ou processo orgânico que não está contemplado na norma não caracteriza necessariamente uma alteração de valor negativo, nem requer de antemão que se intervenha a fim de que o estado fisiológico seja restaurado. $\mathrm{O}$ que sai da norma é, a princípio, apenas aquilo que se afasta da grande maioria das pessoas com as quais se é comparado ${ }^{16}$.

No entanto, a coincidência entre norma e média objetivamente calculada ainda orienta a formulação de protocolos, diretrizes e instrumentos de assistência. Nesse contexto, o problema que se coloca é como contemplar em nossas práticas a variabilidade dos corpos e organismos sem interpretá-la negativamente à luz das generalizações. Tomemos como exemplo um instrumento amplamente utilizado para embasar a assistência obstétrica a partir da fase ativa do trabalho de parto. $\mathrm{O}$ partograma clássico consiste em um gráfico impresso no qual a dilatação em centímetros é registrada em função do tempo, fornecendo-nos um recurso para visualizar a evolução do processo em comparação ao parto eutócico, isto é, o parto normal. O gráfico é composto por duas linhas: uma de alerta e uma de ação. A linha de alerta indica que o trabalho de parto 
registrado no gráfico apresenta um progresso $10 \%$ mais lento que trabalho de parto normal em mulheres primigestas. A linha de ação é localizada algumas horas depois, geralmente duas ou quatro, indicando necessidade de pronto manejo do trabalho de parto mais lento que o normal17. Desse modo, dependendo da evolução da dilatação cervical ao longo do tempo, o próprio gráfico indicará a necessidade de intervenções.

Os parâmetros que embasam esse instrumento e outros protocolos são resultado das tentativas da obstetrícia científica de determinar o que é o parto normal. Em uma das análises estatísticas mais emblemáticas, Emanuel Friedman ${ }^{18}$ dividiu o trabalho de parto em fases e descreveu as relações normais entre dilatação e tempo em mulheres primigestas. Utilizando como referência aquilo que chamou de curva média do trabalho de parto, Friedman ${ }^{18}$ definiu os limites do trabalho de parto normal com base nas alterações estatísticas da relação média entre dilatação cervical e tempo. $\mathrm{O}$ autor foi além: excluindo os dados de trabalhos de parto com intercorrências, projetou a progressão ideal: trabalhos de parto sem intercorrências. Segundo tais parâmetros, o parto normal deve progredir na fase ativa com dilatação de $1 \mathrm{~cm} /$ hora. Se progride em velocidade inferior, caracteriza distócia funcional ${ }^{19}$. Recentemente, os parâmetros do trabalho de parto normal foram revistos e atualizados ${ }^{20}$. As atualizações da norma, entretanto, não deslocam seu alicerce da noção de normatividade estatística.

Por um lado, o uso de um partograma pode contribuir para nortear intervenções no momento oportuno e, consequentemente, melhorar o desfecho obstétrico ${ }^{21}$; por outro, uma vez que o normal não pode ser aprisionado na média - assim como o parto normal não é necessariamente o parto médio -, guiar todo o processo de tomada de decisão e ação sem considerar outros sinais do bem-estar materno-fetal pode, na verdade, levar a intervenções em partos normais mais lentos.
Os corpos femininos colocam em questão essa normatividade estatística e nos convocam a pensar naquilo que Canguilhem ${ }^{16}$ chamou de relatividade individual do normal. Diante disso, o desafio que se coloca é determinar se há necessidade de intervenção durante o trabalho de parto e quais serão os critérios utilizados no processo de tomada de decisão e ação. O conhecimento produzido pela obstetrícia científica e os instrumentos e protocolos que a fundamentam podem, sem dúvida, servir como ferramentas de apoio para a prática obstétrica, uma vez que, de certo modo, refletem aquilo que é mais frequente. Não obstante, devemos reconhecer que nem todo parto normal será contemplado pelos critérios de normalidade da obstetrícia tradicional.

Apesar de se orientar pelo princípio da objetividade inerente ao conhecimento científico, a objetividade seria apenas uma promessa nesse modelo. Em primeiro lugar, um conhecimento objetivo sobre o corpo feminino pretende ser aplicável a todas as mulheres, sem se prender a "peculiaridades pessoais"14(18). Contudo, seria arbitrário restringir a norma à média, de modo que a objetividade se desvaneceria na determinação de uma normalidade global' ${ }^{16}$. Em segundo lugar, a pretensão de universalidade inerente à objetividade científica normaliza os corpos femininos e as experiências de parturição; e, ao fazê-lo, insere o corpo feminino nas relações de poder. Logo, considerada criticamente, sequer encontramos aquela pretensa neutralidade que sustentaria a objetividade tradicional.

Tal objetividade do ponto de vista único, por meio da qual, segundo Haraway 22, apropria-se e se ordena toda a diferença, não é, todavia, nossa única alternativa. Contestamos essa noção de objetividade na medida em que deixa pouco espaço para a singularidade e a particularidade de cada corpo. Se pretendemos operacionalizar uma prática obstétrica que seja sensível às necessidades de cada mulher parturiente, é preciso ressignificá-la. 


\section{Ressignificando a objetividade: contribuições das epistemologias feministas}

Conforme já afirmamos, não pretendemos recusar toda objetividade, nem dispensar os conhecimentos já produzidos sobre o processo de parturição no âmbito da obstetrícia científica. Antes, buscamos ressignificar a objetividade em nossos próprios termos, de modo que possamos fazer, dos conhecimentos produzidos sobre o parto, um uso a favor das mulheres. Isso implica, conforme destaca Harding ${ }^{23}$ a propósito de uma ciência feminista, utilizá-los para atender nossas necessidades reais, não para implementar práticas de controle de nossos corpos.

Desse modo, acreditamos que uma assistência verdadeiramente adequada ao modelo humanizado só pode se realizar, como tal, ao assimilar em sua fundamentação uma visão feminista de objetividade. Tendo em vista que os critérios que maximizam a objetividade na ciência tradicional resultam em posições e práticas sexistas e androcêntricas ${ }^{24}$, implementar uma alternativa ao modelo hegemônico requer posicionamentos e práticas que, por sua vez, contraponham-se a tais princípios sexistas e androcêntricos da obstetrícia moderna. Contrastando com a maneira pela qual a ciência tradicional define o que é objetividade e legitima ou não certos conhecimentos por meio dela, Sandra Harding ${ }^{24}$ propõe a noção de uma objetividade forte, que seria fruto tanto do gesto de situar o conhecimento nas condições em que ele é produzido quanto do esforço de responder às questões concretas relacionadas com as condições de vida das pessoas.

Nesse sentido, é necessário situar a produção de conhecimento e os critérios utilizados para definir o que conta como conhecimento válido nas relações de poder. Uma vez que o fazemos, torna-se fácil compreender que o corpo feminino tem sido posicionado como mero objeto, e o modo como ele é performado nos diferentes campos de saber pouco tem a dizer desse corpo desde a perspectiva das mulheres. Antes, os discursos forjados no âmbito das ciências, inclusive da medicina com pretensões científicas, acabam contribuindo para que ele possa ser regulado e controlado. Conforme já nos alertou Foucault ${ }^{25}$, saber e poder estabelecem entre si uma intrínseca conexão, de modo que não há relação de poder sem correlações com um campo de saber nem saber que não suponha tampouco constitua relações de poder. Desse modo, a questão que se coloca é a seguinte: como o conhecimento produzido sobre os corpos femininos pode ser utilizado a favor das mulheres? Não para controlar o processo de parturição e adequá-lo aos parâmetros idealizados, mas para resolver problemas concretos. É difícil definir de antemão o que seriam esses problemas concretos, já que cada trabalho de parto tem uma dimensão singular que escapa aos conhecimentos generalizáveis sobre esse processo. No entanto, tendo em vista que a assistência que propomos tem como objetivo preservar a vida das mulheres e possibilitar uma experiência de parturição satisfatória, é possível afirmar que nos referimos a um manejo dos riscos de morbimortalidade materna que leve em consideração os desejos e as necessidades de cada mulher. Como detectar tais problemas é o que veremos mais abaixo, com a proposta de uma prática obstétrica situada.

Na esteira das reflexões de Harding, Donna Haraway 22 nos fornece uma imagem potente da objetividade como conhecimento localizado. Localizar o conhecimento pressupõe um corpo, por meio do qual se possui um ponto de vista finito. Essa noção sugere que a confiabilidade de um conhecimento é resultado da perspectiva parcial, não de uma visão que pretende dar conta da totalidade. A finitude de um ponto de vista e a parcialidade da perspectiva permitiriam produzir um conhecimento mais adequado a certo objeto, sem as distorções que uma pretensão prévia de universalidade traria. $\mathrm{O}$ aspecto parcial da produção de conhecimento, que seria um "viés desqualificador"22(7) no âmbito da ciência tradicional, maximizaria sua objetividade. 
Levando em consideração as reflexões feministas sobre objetividade e a validade e confiabilidade dos conhecimentos que produzimos sobre os corpos femininos, faz-se fundamental reconhecer quem é essa pessoa produtora de conhecimento no contexto de assistência ao parto e situá-la em relação à mulher parturiente. Isso requer um exercício reflexivo sobre os princípios que baseiam nossas práticas, nossos posicionamentos e como nos situamos nas relações de poder, pois a assistência que oferecemos às mulheres gestantes e parturientes está impregnada de nossas vivências e experiências, sendo, enfim, afetada pelos eixos de diferenciação que perpassam nossos corpos e que nos introduzem nas relações de poder. Elas não são práticas desde "lugar nenhum"22(18), mas de pessoas que perceberão os sinais do corpo de cada mulher e os interpretará. Situar-se em relação às mulheres parturientes também deve implicar que as reconheçamos como produtoras de conhecimento legítimo sobre seus próprios corpos. Desse modo, a relação entre profissional e mulher deverá ser de parceria e tomada de decisão conjunta, não de autoridade. Por fim, adotar uma noção feminista de objetividade situada implica o exercício de não universalizar a assistência, adotando condutas e tomando decisões ancoradas nos corpos das mulheres que se encontram diante de nós. Objetividade feminista na atenção ao parto significa acolher a singularidade de cada corpo.

O corpo nos posiciona no mundo, e por intermédio dele somos inseridas/os nas relações de poder e de conhecimento. O corpo é o próprio aparato, ou seja, a matriz por meio da qual produzimos conhecimento. Se na lógica da obstetrícia moderna o corpo é apenas o objeto que deve ser esmiuçado e controlado, nesse novo modelo, ele se torna aquilo que Haraway 22(40) chamou de "ator material-semiótico" na produção de conhecimento.

\section{Corpos em relação: o conhecimento sensível na atenção ao parto}

Haraway ${ }^{22}$ afirma que a objetividade tradicional deve negar a agência dos objetos na produção de conhecimento. Já a versão feminista, maximizada por seu caráter situado, reconhece a agência dos objetos que buscamos conhecer. Se pretendemos produzir um conhecimento objetivo sobre o parto que possa embasar uma prática alternativa ao modelo tecnocrático, o corpo feminino não deve figurar apenas como objeto passivo e inerte a ser controlado, mas também como ator e agente na produção de conhecimento.

Se pretende ser objetiva e adequada, nenhuma conduta ou decisão deve ser externa ao corpo da mulher parturiente e suas necessidades. É a partir do corpo de cada mulher que se encontra diante de nós - e em aliança com ele - que o conhecimento que legitima toda decisão e ação na assistência ao parto deve ser produzido. Os parâmetros universalizantes de normalidade em relação ao tempo de progressão do trabalho de parto, desde que atualizados, são úteis para orientar nossas práticas, mas podem não contemplar partos que, ainda que mais lentos, são normais e não colocam em risco o bem-estar materno fetal. Segundo estudo recente ${ }^{\mathbf{2 6}}$, o trabalho de parto é um fenômeno extremamente variável, e a avaliação da dilatação cervical em função do tempo é um mau preditor de desfechos adversos graves.

Nesse contexto, seria mais profícuo se nos orientássemos por outros sinais que o corpo nos dá para avaliar a normalidade do processo ou se há necessidade de intervenção. Se reconhecemos que a duração do parto pode variar além daquela que determinam manuais e livros de obstetrícia - ou mesmo evidências científicas atualizadas -, o primeiro aspecto a se considerar na avaliação da normalidade da duração do parto é o bem-estar materno fetal. 
Muitos são os sinais que o corpo feminino nos dá por meio da ausculta, do toque ou de uma observação atenciosa. O monitoramento dos sinais vitais e do bem-estar passa a ser aliado $\mathrm{da} / \mathrm{o}$ profissional que faz um acompanhamento constante e permanece ao lado da mulher a fim de evitar qualquer desfecho negativo. Portanto, para captá-los, é preciso dedicação e sentidos aguçados. Para a avaliação do bem-estar fetal, recomenda-se ausculta intermitente, a cada 15 a 30 minutos; e, no período expulsivo, a cada 5 minutos ${ }^{27}$. A audição deve estar atenta à presença de taquicardia, desacelerações tardias ao pico das contrações e desacelerações frequentes, bem como à ausência de acelerações compensatórias após desacelerações. Já no período expulsivo, a ocorrência de bradicardia é esperada e deve ser interpretada em relação à iminência do nascimento.

Entretanto, avaliar a normalidade da progressão do trabalho de parto não se restringe a monitorar o bem-estar fetal. É necessário estar atenta/o a outros elementos, como a efetividade das contrações uterinas. Para tanto, o tato entra em cena. As mãos devem ser posicionadas no abdome da mulher parturiente, próximas ao fundo uterino, percebendo o início das contrações, sua intensidade, duração e frequência. À luz da própria experiência associada ao conhecimento científico disponível sobre o trabalho de parto, a/o profissional poderá avaliar se as contrações são satisfatórias ou requerem o uso de recursos farmacológicos e/ou não farmacológicos para a condução do processo. Por fim, é necessário observar atentamente o bem-estar dessa mulher, colocando em prática uma escuta atenta às suas queixas. Ouvir o que ela tem a dizer, confiando no conhecimento que possui sobre o próprio corpo, possibilita identificar com agilidade possíveis intercorrências.

A/O profissional com sentidos aguçados também pode evitar que procedimentos invasivos e incômodos sejam realizados com uma frequência desnecessária. Segundo Narchi et al. ${ }^{28}$, a linha púrpura tem relação direta com a dilatação cervical. Se presente, pode ser utilizada para medi-la, contribuindo para diminuir a frequência de exames vaginais. Essa mancha de coloração arroxeada começa na região perianal das mulheres em trabalho de parto e avança no sentido ascendente à medida que dilatação progride. Ao alcançar $10 \mathrm{~cm}$, indica que a dilatação está completa. A decida e o posicionamento fetal também podem ser observados por meio da mudança na forma da barriga da mulher e no local que posicionamos o sonar para realizar a ausculta fetal. No início do trabalho de parto, auscultaremos na lateral da barriga, mais próximo à linha do umbigo. Conforme o período expulsivo se aproxima, o sonar será posicionado próximo à sínfise púbica. Outros sinais também evidenciarão a iminência do nascimento: a agitação, o aumento da transpiração e os puxos espontâneos mostram que o corpo está pronto para parir.

O corpo é central nesse modelo de assistência. No entanto, os corpos femininos também não 'falam por si mesmos'. Se há um corpo pronto a dar sinais, há, também, um sujeito corporificado pronto a percebê-los, interpretá-los e planejar a assistência, de modo que uma assistência ao parto efetiva se dê mediante corpos em relação. Considerar tais sinais requer que reconheçamos o caráter legitimo e válido do conhecimento sensível, um conhecimento fundamentalmente encarnado.

Ao reconhecer a centralidade do conhecimento encarnado na assistência ao parto, tentamos, assim como algumas feministas que nos precedem, escapar dos dualismos que estão na base da epistemologia e filosofia ocidentais. Donna Wilshire ${ }^{29}$ afirma que a teoria do conhecimento predominante na modernidade ocidental é tanto hierárquica como piramidal, colocando-se como um sistema que valoriza algumas modalidades de produção de conhecimento em detrimento de outras. Esse modelo coloca em oposição razão e conhecimento sensivel, associando aquela ao conhecimento verdadeiro e este ao domínio da ignorância.

Ao longo da história, grandes pensadores contribuíram para a desvalorização dessa modalidade de produção de conhecimento. 
Inaugurando a Idade Moderna, Descartes ressignificou o dualismo afirmando a completa independência entre mente, produtora de conhecimento, e o corpo máquina. No entanto, as raízes do caráter masculinista dessa tradição remontam ao pensamento aristotélico, segundo o qual a razão, prerrogativa masculina, seria fonte do conhecimento verdadeiro e superior. Por outro lado, o conhecimento sensível, associado ao feminino, seria de ordem inferior ${ }^{29}$.

Desse modo, consolidar uma prática feminista requer uma nova formulação dos termos pelos quais reconhecemos a legitimidade de determinado tipo de conhecimento, operando um deslocamento do campo do dualismo hierárquico em direção ao campo da multiplicidade. Não se trata, portanto, de recusar a razão, tampouco de afirmar a sensibilidade como forma de conhecimento essencialmente feminina. Trata-se de reconhecer, conforme afirma Wilshire ${ }^{29}$, que o conhecimento ou a consciência saudável do mundo vêm de muitos tipos de saber operando em conjunto ou em turnos, com nenhum deles recebendo mais valor do que os outros.

\section{Considerações finais}

Inicialmente, contextualizamos o modelo tecnocrático em sua matriz de condições de produção. Três elementos são fundamentais para sua consolidação: as práticas de controle do corpo feminino características da biopolítica; a emergência e a consolidação da medicina científica; e, por fim, o caráter universalizante do conhecimento científico e da noção hegemônica de objetividade. Em muitos momentos, utilizamos os termos obstetrícia científica e modelo tecnocrático como sinônimos. No entanto, quando contrastada à medicina baseada em evidências - que, inclusive, vem contribuindo para que algumas práticas consolidadas pelo modelo tecnocrático sejam repensadas -, parece-nos que o modelo hegemônico se revela muito mais fundamentado na autoridade que emana da ciência do que em qualquer tipo de conhecimento objetivo. Desse modo, questionamos se o modelo hegemônico não está, na realidade, baseado no princípio da autoridade, consolidando práticas de controle dos corpos femininos que possibilita.

Apesar dessa contradição, a objetividade é o princípio convocado para validar as práticas características do modelo tecnocrático. Ressignificar a noção de objetividade torna possível vislumbrar um novo modelo, no qual os corpos femininos não desaparecem em favor de um sujeito soberano que o decodifica e detém a verdade sobre ele. Toda a assistência seria ancorada nas necessidades concretas de cada mulher, expressas em seus corpos por meio de sinais sutis, detalhes que podem orientar o cuidado e a ação diante de possíveis intercorrências. Nesse contexto, uma obstetrícia a favor das mulheres se consolidaria na relação entre elas e as/os profissionais qualificadas/os, aqui entendidas/os como sujeitos encarnados prontos a captar tais sinais e interpretá-los.

Por fim, não recusamos o conhecimento produzido pela medicina científica. Pelo contrário, o uso das evidências científicas não é incompatível com uma proposta de atenção obstétrica situada. No entanto, recomendamos que seu uso se dê de maneira reflexiva, evitando que as evidências se institucionalizem como um novo argumento de autoridade ou que se estabeleçam relação de soberania com outros saberes. Antes, cumprem um papel ainda mais importante quando se apresentam como uma das muitas fontes de conhecimento utilizadas para a tomada de decisão, operando em conjunto com outros modos legítimos de produção de conhecimento.

Concluímos, dessa forma, que as intervenções devem ser realizadas em função da necessidade individual e que o processo de tomada de decisão durante o trabalho de parto deve se dar na relação entre profissional e mulher. Diante disso, buscamos apresentar um aparato teórico que pudesse fundamentar aquilo que, inspiradas pelas reflexões de Haraway, chamamos de uma prática situada, na qual profissionais familiarizadas/os com os conhecimentos científicos possam aplicá-los 
de maneira específica em cada trabalho de parto, respeitando as necessidades da parturiente e do feto, e não de maneira protocolar, de modo que o processo de tomada de decisão e ação esteja centrado no corpo feminino, orientado à luz dos sinais que uma monitoração cuidadosa deste nos fornece.

\section{Referências}

1. Jordan B. Technology and Social Interaction: Notes on the Achievement of Authoritative Knowledge. Technical Report IRL92-0027. Palo Alto, CA: Institute for Research on Learning; 1992. [acesso em 2020 junho 20]. Disponível em: http://anthropology.msu. edu/anp270-us15/files/2015/05/Authoritative-Knowledge-Jordan-1992.pdf.

2. Davies-Floyd R. The technocratic, humanistic, and holistic paradigms of childbirth. Inter. J. Gynec. Obst. 2001; (75):5-23.

3. Spink MJ. As origens históricas da obstetrícia moderna. In: Psicologia social e saúde: práticas, saberes e sentidos. 9. ed. Petrópolis: Vozes; 2013.

4. Davis-Floyd R, Davis E. Intuition as authoritative knowledge in midwifery and homebirth. Med. Anthropol. quart. 1996; 10(2):237-269.

5. Diniz CSG. Humanização da assistência ao parto no Brasil: os muitos sentidos de um movimento. Ciênc.

\section{Colaboradoras}

Mortelaro PK (0000-0002-9253-7096)* e Cirelli JF (0000-0001-9066-8538)* contribuíram igualmente para a elaboração do manuscrito.
Saúde Colet. 2005; 10(3):627-637.

6. Atallah AN, Castro AA. Medicina baseada em evidências: o elo entre a boa ciência e a boa prática. Rev. imag. 1998; 20(1):5-9.

7. Foucault M. Em defesa da sociedade. Curso no Collège de France (1975-1976). São Paulo: Martins Fontes; 2005.

8. Palharini LA, Figueirôa SFM. Gênero, história e medicalização do parto: a exposição "Mulheres e práticas de saúde”. HCS-Manguinhos. 2018; 25(4):10391061.

9. Foucault M. A história da sexualidade: a vontade de saber. Rio de Janeiro; São Paulo: Paz \& Terra; 2015.

10. Diniz CSG. Atenção ao parto e relações de gênero: elementos para uma releitura médico-social. [dissertação]. [São Paulo]: Universidade de São Paulo; 2007. 210 p.
*Orcid (Open Researcher and Contributor ID). 
11. Rohden F. Uma ciência da diferença: sexo e gênero da medicina da mulher. 2. ed. Rio de Janeiro: Editora Fiocruz; 2009.

12. Martins APV. A ciência dos partos: visões do corpo feminino na constituição da obstetrícia científica no século XIX. Rev. Estud. Femin. 2005; 13(3):645-665.

13. Mott ML. Assistência ao parto: do domicílio ao hospital (1830-1960). Proj. História. 2002; (25):197-219.

14. Culpani A. A objetividade científica como problema filosófico. Cad. Cat. Ens. Fís. 1989; (6):18-29.

15. Silva F, Nucci M, Nakano AR, et al. "Parto ideal”: medicalização e construção de uma roteirização da assistência ao parto hospitalar no Brasil em meados do século XX. Saúde Soc. 2019; 28(3):171-184.

16. Canguilhem G. O normal e o patológico. 6. ed. Rio de Janeiro: Forense Universitária; 2009.

17. Lavender T, Hart A, Smyth RMD. Effect of partogram use on outcomes for women in spontaneous labour at term. Coch. Data. Syst. Reviews. 2013; 10(7).

18. Friedman E. Primigravid labor: a graphicostatistical analysis. Obstet Gynecol. 1955; 6(6):567-589.

19. Montenegro CAB, Rezende Filho J. Obstetrícia fundamental. 13. ed. Rio de Janeiro: Guanabara-Koogan; 2014.

20. Zhang J, Landy HJ, Branch DW, et al. Contemporary Patterns of Spontaneous Labor With Normal Neonatal Outcomes. Obstet Gynecol. 2010; 116(6):12811287.

21. Rocha IMS, Oliveira SMJV, Schneck CA, et al. O partograma como instrumento de análise da assistência ao parto. Rev Esc Enferm USP. 2009; 43(4):880-888.
22. Haraway D. Saberes localizados: a questão da ciência para o feminismo e o privilégio da perspectiva parcial. Cadernos Pagu. 1995; (5):07-41.

23. Harding S. Is there a feminist method? In: Harding, S. Feminism and Methodology. Bloomington: Indiana University Press; 1987.

24. Harding S. Objetividade mais forte para ciências exercidas a partir de baixo. Tradução: Melo RF. Em construção: arquivos de epistemologia história e estudos da ciência. 2019; 5:143-162.

25. Foucault M. A ordem do discurso. São Paulo: Editora Loyola; 2010.

26. Souza JP, Oladapo OT, Fawole B, et al. Cervical dilatation over time is a poor predictor of severe adverse birth outcomes: a diagnostic accuracy study. BJOG. 2018; 125(8):991-1000.

27. World Health Organization. WHO recommendations: intrapartum care for a positive childbirth experience. Genebra: WHO; 2018.

28. Narchi NZ, Camargo JCS, Salim NR, et al. Utilização da "linha púrpura" como método clínico auxiliar para avaliação da fase ativa do trabalho de parto. Rev. Bras. Saúde Mater. Infant. 2011; 11(3):313-322.

29. Wilshire D. Os usos do mito, da imagem e do corpo da mulher na re-imaginação do conhecimento. In: Jaggar MJ, Bordo SR, organizadoras. Género, corpo, conhecimento. Rio de Janeiro: Rosa dos Tempos; 1997. p. 101-125.

Recebido em 31/08/2020

Aprovado em 28/06/2021

Conflito de interesses: inexistente

Suporte financeiro: Conselho Nacional de Desenvolvimento

Científico e Tecnológico (CNPq. Processo número 140189/2018-1). 